\title{
Diseases associated with Flammer Syndrome: An Update
}

\author{
Katarzyna Konieczka ${ }^{1 *}$, Josef Flammer ${ }^{1}$ and Carl Erb ${ }^{2}$ \\ ${ }^{1}$ Department of Ophthalmology, University of Basel, Switzerland \\ ${ }^{2}$ Eye Clinic Wittenbergplatz, Germany
}

*Corresponding author: Katarzyna Konieczka, Department of Ophthalmology, University of Basel, Mittlere Strasse 91 CH-4056 Basel, Switzerland

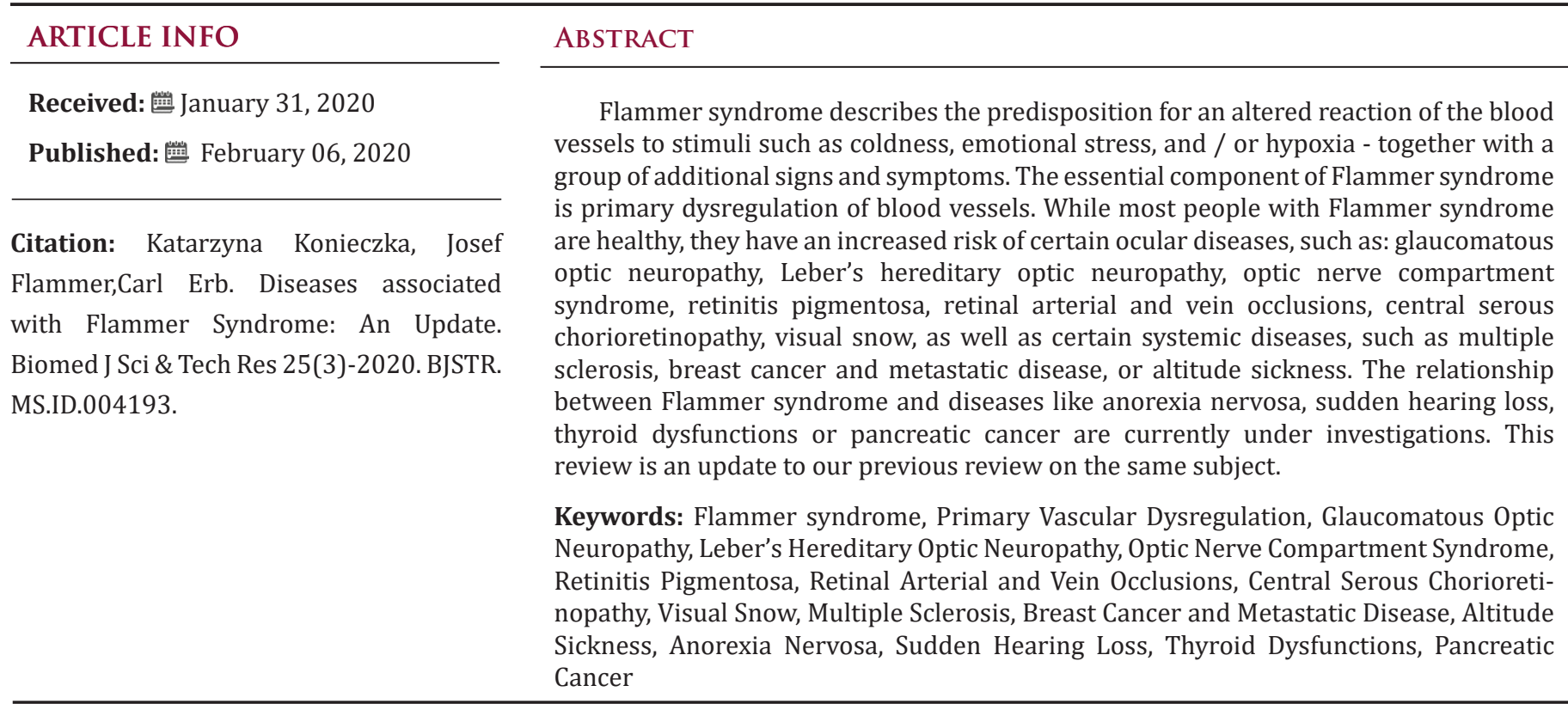

\section{Introduction}

Although some diseases have only one cause, most diseases are caused by the interaction of many factors. It is common for environmental factors to interact with genetic factors. The Flammer syndrome is the phenotype of a genetic predisposition to react differently to stimuli. This predisposition protects affected people from certain diseases but makes them more susceptible to other diseases. This review is an update on our previous review on diseases potentially related to Flammer syndrome [1].

\section{Flammer Syndrome}

Flammer syndrome [FS] describes the predisposition for an altered reaction of the blood vessels to stimuli such as coldness, emotional stress, and / or hypoxia - together with a group of additional signs and symptoms [2-5]. The essential component of FS is primary dysregulation of blood vessels [3]. The term "Flammer syndrome" [2] was introduced in the scientific literature only recently $[2,6,7]$, but many aspects of FS were described in older publications under the terms "vasospastic syndrome" [8] or "primary vascular dysregulation" [3]. The history of the discovery of the FS and its introduction into the scientific literature have been described in a recent review [9]. Most people with FS are healthy. Those affected often have symptoms, but because they are unaware of the syndrome, they do not realize that these symptoms are interconnected. Moreover, most people with FS have had symptoms since their youth, and they have a mother or a father who also displayed them. Therefor they consider them as normal. People with FS have also often learned to alleviate the symptoms, for example by wearing bed socks at night. Clinical observations suggest that FS 
may even have protective effects resulting in a good life expectancy, because they have less often classical cardiovascular risk factors such as high blood pressure, dyslipidemia or overweight. People with FS also seem to be protected against metabolic syndrome [10], probably due to increased adiponectin levels [11]. Of course, arterial hypertension, hypercholesterolemia or even obesity can also occur in FS people, especially when they get older, but simply much less often than in other people. The same therefore also applies to classical cardiovascular diseases. However, people with FS are at certain risk for other diseases. These include some eye diseases, but also multiple sclerosis, altitude sickness and certain cancers. While many relationships have not yet been clarified and are currently being studied in a variety of research projects, we summarize here the already known facts.

\section{Ocular Signs of FS}

Josef Flammer - the clinician and scientist who discovered the FS - is an ophthalmologist; therefore, the connections between FS and ocular diseases have been the most heavily studied. The term "Flammer syndrome" was finally introduced in the literature by Katarzyna Konieczka [2,6,7], also an ophthalmologist. Thus, we will discuss the ocular effects of FS first. The symptoms and signs of FS occur in affected people even when they are healthy, but they occur more frequently and more severely when the FS individuals have diseases associated with FS. This also applies to ocular signs. In the eyes of individuals with FS, the following signs are often observed: Reduced autoregulation of ocular blood flow [12], with the consequence that the blood supply to the eye is mainly determined by the perfusion pressure. This in turn explains why in these people the blood supply to the eye correlates with the blood flow in the fingers [13]. Further sings are stiffening of retinal vessels [14] and increased spatial vascular irregularity [15]. The reaction of retinal vessels to flickering light is diminished in individuals with FS [16]. This is an indirect sign of a kind of endotheliopathy [17].

Another ocular sign of FS are optic disc hemorrhages, which occur often in FS patients with glaucoma, but sometimes also in individuals with FS without glaucoma [18]. The retinal venous pressure can be higher than the intraocular pressure in various diseases, such as glaucoma, especially if these patients have FS [19]. The glial cells, particularly the astrocytes in the retina are more frequently and more strongly acitivated in glaucoma patients with FS than without FS [20]. Individuals with FS sometimes feel pain, particularly behind the upper eyelid [21] due to relative hypoxia in the ciliary muscle. Relatively rare, but very disturbing for the patients, are scintillations - described in the literature as visual snow - which are perceived with open and closed eyes. While our clinical observations are impressive, the exact relationship between FS and visual snow has yet to be demonstrated in future studies.

\section{Ocular Diseases Related to FS}

Here we discuss diseases with more or less known causes, which nevertheless occur more frequently in people with FS. We must therefore assume that FS can play a role in the occurrence or course of these diseases [1]. This concerns the following diseases: glaucomatous optic neuropathy, Leber's hereditary optic neuropathy, optic nerve compartment syndrome, retinitis pigmentosa, vascular occlusions, central serous chorioretinopathy, and visual snow [1].

Glaucomatous optic neuropathy [GON] is characterized by an excavation of the optic nerve head [ONH], as well as a loss of nerve fibers, with corresponding visual field deficits. There are many known risk factors for GON; the best known is elevated intraocular pressure, which in turn has many different causes. Other factors that influence the occurrence or course of GON include vascular factors, especially primary vascular dysregulation [3], the essential component of FS. This is especially true for normal tension glaucoma [22]. Here we already understand the connections quite well. A component of primary vascular dysregulation is an impaired regulation of ocular perfusion. As a result, fluctuations of intraocular pressure or blood pressure lead to instable oxygen supply to the eye. This in turn boosts oxidative stress - particularly in the mitochondria of the $\mathrm{ONH}$ - and activates astrocytes. All this ultimately leads to cell death and $\mathrm{ONH}$ excavation. Individuals with FS also have on average lower ocular perfusion due to increased retinal venous pressure [19], increased vascular resistance, and decreased blood pressure [23]. This pathogenetic concept of GON development has been described in previous reviews [24,25], as well as the relationship between glaucoma and FS [22,26-29].

Leber's hereditary optic neuropathy [LHON] is a rare inherited disease resulting from mutations in maternal mitochondrial DNA [mtDNA]. LHON leads to acute or subacute visual loss beginning in one eye, with the fellow eye becoming similarly affected within weeks. In the late stage, the $\mathrm{ONH}$ is pale, with shallow excavation. This has triggered discussions about whether there is a link between LHON and normal-tension glaucoma [30]. Mitochondrial dysfunction is a major component in both. Based on our clinical observations, most patients with LHON also have FS [3,31]. It is conceivable that the oxidative stress induced by unstable oxygen supply escalates the risk of a mtDNA mutation to manifest clinically [31].

Optic nerve compartment syndrome [ONCS] [32,33] is a pathological condition in which the cerebrospinal fluid [CSF] in the subarachnoid space surrounding the optic nerve is partially or totally segregated from the CSF in the intracranial subarachnoid space, increasing the local CSF - pressure and thereby distending the optic nerve sheath. The pathogenesis of this condition remains unclear. Clinical observations reveal that most patients with both glaucoma and ONCS, also suffer from FS [3], [33,34]. We assume that the locally increased oxidative stress leads to swelling of the arachnoid trabeculae, septa, and pillars in the subarachnoidal space of the optic nerve. Inaddition, a locally elevated endothelin level constricts the lymph vessels and reduces the outflow of the cerebrospinal fluid. This explains the positive effect of calcium channel blockers [34]. 
There is also a connection between retinitis pigmentosa [RP] and FS [35-37]. RP comprises a heterogeneous group of hereditary diseases that lead to a loss of retinal cell function. Primarily the photoreceptors of the peripheral retina are affected, later the whole retina, including the macula, may be affected. That RP has a genetic cause is indubitable [38], but that doesn't rule out the possibility that other factors influence the manifestation and progression of the disease [35]. One of the potential factors is reduced ocular blood flow [39-41]. Reduced ocular blood flow in RP is partly but not entirely explained by tissue atrophy. The assumption of an additional reduction of blood flow is supported by observations that the ocular blood flow is reduced already in early stages and is not confined to the eye $[39,42]$. We described the hypothesis that FS is one of the major causes for such a primary component of blood flow reduction in RP [35]. Thereby oxidative stress, induced by unstable blood flow in FS subjects, may play an important role [43].

Also potentially related to FS are vascular occlusions. The major causes of arterial occlusions such as the retinal arterial occlusions are thrombi or emboli due to atherosclerosis. Nevertheless, such occlusions can sometimes occur in young patients in the absence of classical vascular risk factors. In our experience, such vascular occlusions can occur in people with FS, especially under psychological stress or strong cold exposure. These occlusions can affect the ONH [44] and, less often, the choroid [45], the cilioretinal vessels [46], and the retina [3]. A relationship between Susac syndrome and FS has also been reported [47]. In addition, retinal and $\mathrm{ONH}$ infarctions have also been described as a perioperative complication in FS patients $[48,49]$.

Retinal vein occlusions were previously believed to be always a consequence of thrombosis. Josef Flammer's research group hypothesized that occlusion may also be a consequence of a local constriction of a retinal vein [50,51]. There are several causes for such a venous constriction, but FS is obviously a predisposing condition [50]. Whereas a mild local venous constriction increases retinal venous pressure, a more pronounced constriction can result in a retinal vein occlusion $[51,52]$. These venous constrictions are induced by vasoconstrictive molecules, particularly endothelin-1. Endothelin is a very strong vasoconstrictor that can diffuse to the veins from neighboring sick arteries or from circulating blood via fenestrated choriocapillaries into the ONH. Under hypoxic conditions, endothelin is also produced in the surrounding tissue. This explains why not only arteriosclerosis, high blood pressure, and increased intraocular pressure but also FS increase the risk for vein occlusions.

Central serous chorioretinopathy [CSCR] is a disease characterized by a serous detachment of the retina in the acute phase. The detachment is the consequence of one or more defects of the outer blood-retina barrier, i.e. the pigment epithelium. Fluid from the choroid thus passes under the retina. The defects usually disappear spontaneously, in certain cases the disease can become chronic. The pathogenesis is still largely unclear. A number of risk factors have beenidentified, for example malegender, corticosteroids usage, psychologic stress, pregnancy, some endocrine disorders, etc. We postulated that FS might be a risk factor for CSCR $[1,3]$. Many of our CSCR patients also had signs and symptoms of FS. A report years ago pointed out that the disease is accompanied by a local vascular dysfunction of the choroid, particularly dilated veins [53]. It has also been reported that the disease occurs more frequently in type - A personalities and manifests itself particularly often in patients who are under psychological stress. We know that typical reaction to stress in individuals with FS is transient vasoconstriction and/ or vasodilatations. In the acute phase, endothelin is significantly elevated in the blood. A postulated local increase of the endothelin concentration can explain the venous stasis in the choroid, as well as the local opening of the external blood-retina barrier [54].

Patients with "visual snow" report continuous tiny dots in the entire visual field similar to the noise of an analogue television. It is a unique visual disturbance clinically distinct from migraine aura, although these patients often also suffer from migraine at the same time [55]. Based on our clinical experience, many patients suffering from visual snow have pronounced symptoms and signs of FS. The causality of this association needs however to be clarified.

\section{Systemic Signs and Symptoms of FS}

FS signs and symptoms occur mainly when related diseases occur, but they can also be present in completely healthy people with FS. For this reason, we will first discuss FS symptoms independent from diseases. The two most prominent symptoms of FS are cold hands and/or feet [8] and low blood pressure [56]. In addition, persons with FS often are very slim [57]. Typically, they take a long time to fall asleep and exhibit a phase delay in the circadian rhythm. The sensation of thirst is reduced, probably caused by slightly elevated levels of endothelin-1 in circulating blood [58]. This suppresses the thirst center in the brain via PG-E2. Individuals with FS are generally more sensitive; they have increased sensitivity to certain drugs [for example to calcium channel blockers or betablockers], increased pain sensation, increased smell sensation, and increased sensitivity to high altitude. Individuals with FS have more frequent headaches and migraines. Persons with FS often suffer from tinnitus and have a tendency toward perfectionism. They also have prolonged blood flow cessation in the nailfold capillaries after cold provocation. People with FS have an autonomic imbalance with sympathetic predominance [59]. Nevertheless, the causal relationship with the vascular dysregulation is unclear, because non-autonomic innervated retinal vessels are also involved in FS [3]. Individuals with FS have altered gene expression [60] and increased systemic oxidative stress [61]. More details can be found in our previous publications [2,3].

\section{General Diseases Related to FS}

Multiple sclerosis [MS] is a demyelinating, degenerative disease of the central nervous system of unknown etiology. Patients with MS suffer significantly more frequent from signs and symptoms of 
FS than controls [3,62], but we still do not know why. There are two options: MS may cause FS symptoms, or people with FS may have a higher risk of developing MS. It is quite interesting that patients with MS often indicate they had symptoms of FS before they developed MS. J. Flammer et al. hypothesized that the clinically undetected microinfarctions may trigger an autoimmune disease [3]. The increased oxidative stress in FS subjects may further contribute to the pathogenesis of MS. In a later stage of the disease, the inflammation induces a secondary vascular dysregulation, which further contributes to the chronic progression of MS [63].

Cancer and metastatic disease: The development of cancer is complex and the cause multifactorial. At present we know little about the connections between FS and the occurrence and course of cancer. Associations with breast cancer have already been published $[64,65]$ and discussed. Intermittent hypoxia and oxidative stress due to FS may contribute to breast cancer and its progression into metastatic disease [66]. In some other tumors, such as pancreatic cancer, we have a clinical suspicion of a connection with FS.

Altitude sickness is a general term encompassing a spectrum of disorders that occur at higher altitudes. The primary cause of altitude sickness is the low oxygen level at higher altitudes that leads to tissue hypoxia and thereby to an increase in hypoxia-inducible factor 1-alpha. This leads to increased expression of several hormones, such as endothelin-1 and erythropoietin. Individuals with FS have both higher plasma levels of endothelin and higher sensitivity to endothelin [67]. Altitude sickness is therefore more pronounced in FS people $[3,68,69]$.

\section{Diseases Under Investigation}

Clinical evidence points out that signs and symptoms of FS often occur in patients with anorexia nervosa. This relationship is presently under investigation. Interestingly, fasting intensifies FS symptoms. This is consistent with the observation that fasting reduces the responses of retinal arteries and veins to flickering light [70]. Clinical observations have also revealed a link between FS and. Tinnitus, sudden hearing loss, and even Ménière's disease. These relationships are also currently under investigation. Patients with both normal tension glaucoma and FS often have

Thyroid dysfunctions. Other patients have antibodies against the thyroid despite normal gland function. Patients with FS also suffer relatively frequently from Hashimoto thyroiditis. Again, subclinical microinfarctions may triggering autoimmunity. The relationship between FS and some heart diseases - such as

Prinzmetal angina - is likely, but has, to the best of our knowledge, not yet been investigated. However, the fact that persons with FS often suffer from silent myocardial ischemia has already been reported [3].

A whiplash trauma is the result of the sudden deceleration or acceleration of the thorax independent of head movement. Such injuries usually occur as a result of a rear-end collision. Symptoms caused by the injury are grouped together as "whiplash associated disorders" and encompass neck pain, headaches, dizziness, and sleep disturbances. In our clinical observations, patients with whiplash trauma have more and longer lasting symptoms when they also suffer from FS. We have a clinical suspicion that there is an association between

Pancreatic cancer and FS. To prove this scientifically, however, we need further data. This relationship is currently being investigated.

\section{Conclusion}

Although FS appears to even protect against certain diseases such as metabolic syndrome and cardiovascular events - there are many indications that it increases the risk for other diseases, such as eye diseases or multiple sclerosis. We have made the clinical observation that FS treatment significantly slows down or even completely stops the progression of visual field damage in patients with glaucoma, particularly normal tension glaucoma. It is however not yet known whether treatment of FS also slows progression of other related diseases.

\section{Disclosures/Conflict of interest}

The authors declare that there is no conflict of interest.

\section{References}

1. Konieczka K, Erb C (2017) Diseases potentially related to Flammer syndrome. The EPMA journal 8(4): 327-332.

2. Konieczka K, Ritch R, Traverso CE, Kim DM, Kook MS, et al. (2014) Flammer syndrome. The EPMA journal 5(1): 11.

3. Flammer J, Konieczka K, Flammer AJ (2013) The primary vascular dysregulation syndrome: implications for eye diseases. The EPMA journal 4(1): 14.

4. Flammer J, Konieczka K, Bruno RM, Virdis A, Flammer AJ, et al. (2013) The eye and the heart. European heart journal 34(17): 1270-1278.

5. Konieczka K, Flammer J (2016) Phenomenology and Clinical Relevance of the Flammer Syndrome]. Klinische Monatsblatter fur Augenheilkunde 233(12): 1331-1336

6. Konieczka K, Fränkl S (2013) Primäre vaskuläre Dysregulation und Glaukom (Primary Vascular Dysregulation and Glaucoma). Z prakt Augenheilkd 34: 207-215.

7. Konieczka K (2014) Flammer Syndrom, In Brähler E, Hoefert HW. Lexikon der Modernen Krankheiten. Medizinisch Wissenschaftliche Verlagsgesellschaft Berlin Deutschland 2014.

8. Saner H, Wurbel H, Mahler F, Flammer J, Gasser P (1987) Microvasculatory evaluation of vasospastic syndromes. Adv Exp Med Biol 220: 215-218.

9. Flammer J, Konieczka K (2017) The discovery of the Flammer syndrome: a historical and personal perspective. The EPMA journal 8(2): 75-97.

10. Konieczka K, Flammer J Glaukom Le glaucome (2017) Swiss Medical Forum 17: 105-112.

11. Park AY, Cha S (2017) Effects of cold sensitivity in the extremities on circulating adiponectin levels and metabolic syndrome in women. BMC Complement Altern Med 17(1): 150.

12. Gherghel D, Orgul S, Dubler B, Lubeck P, Gugleta K, et al. (1999) Is vascular regulation in the central retinal artery altered in persons with vasospasm? Arch Ophthalmol 117(10): 1359-1362. 
13. Mozaffarieh M, Osusky R, Schotzau A, Flammer I (2010) Relationship between optic nerve head and finger blood flow. Eur J Ophthalmol 20(1): 136-141.

14. Oettli A, Gugleta K, Kochkorov A, Katamay R, Flammer J, et al. (2011) Rigidity of retinal vessel in untreated eyes of normal tension primary open-angle glaucoma patients. Journal of glaucoma 20(5): 303-306.

15. Kochkorov A, Gugleta K, Zawinka C, Katamay R, Flammer J, et al. (2006) Short-term retinal vessel diameter variability in relation to the history of cold extremities. Investigative ophthalmology \& visual science. 47(9): 4026-4033.

16. Gugleta K, Zawinka C, Rickenbacher I, Kochkorov A, Katamay R, et al. (2006) Analysis of retinal vasodilation after flicker light stimulation in relation to vasospastic propensity. Investigative ophthalmology \& visual science 47(9): 4034-4041.

17. Barthelmes J, Nagele MP, Ludovici V, Ruschitzka F, Sudano I, et al (2017) Endothelial dysfunction in cardiovascular disease and Flammer syndrome-similarities and differences. The EPMA Journal 8(2): 99-109.

18. Grieshaber MC, Terhorst T, Flammer J (2006) The pathogenesis of optic disc splinter haemorrhages: A new hypothesis. Acta Ophthalmol Scand 84(1): 62-68

19. Fang L, Baertschi M, Mozaffarieh M (2014) The effect of flammersyndrome on retinal venous pressure. BMC ophthalmology 14: 121.

20. Grieshaber MC, Orgul S, Schoetzau A, Flammer J (2007) Relationship between retinal glial cell activation in glaucoma and vascular dysregulation. Journal of glaucoma 16(2): 215-219.

21. Flammer J, Haefliger IO, Orgul S, Resink T (1999) Vascular dysregulation: a principal risk factor for glaucomatous damage? Journal of glaucoma 8(3): 212-219.

22. Konieczka K, Choi HJ, Koch S, Fankhauser F, Schoetzau A, et al. (2017) Relationship between normal tension glaucoma and Flammer syndrome. The EPMA journal 8(2): 111-117.

23. Binggeli T, Schoetzau A, Konieczka K (2018) In glaucoma patients, low blood pressure is accompanied by vascular dysregulation. EPMA Journal.

24. Flammer J, Mozaffarieh M (2007) What is the present pathogenetic concept of glaucomatous optic neuropathy? Surv Ophthalmol 52 Suppl 2: S162-73.

25. Flammer J (1994) The vascular concept of glaucoma. Surv Ophthalmol 38 Suppl: S3-6.

26. Flammer J, Orgul S, Costa VP, Orzalesi N, Krieglstein GK, et al. (2002) The impact of ocular blood flow in glaucoma. Progress in retinal and eye research 21(4): 359-393.

27. Konieczka K, Frankl S, Todorova MG, Henrich PB (2014) Unstable oxygen supply and glaucoma. Klinische Monatsblatter fur Augenheilkunde 231(2): 121-126

28. Gasser P, Flammer J (1991) Blood-cell velocity in the nailfold capillaries of patients with normal-tension and high-tension glaucoma. American journal of ophthalmology 111(5): 585-588.

29. Terelak Borys B, Grabska Liberek I, Schoetzau A, Konieczka K (2019) Transient visual field impairment after cold provocation in glaucoma patients with Flammer syndrome. Restor Neurol Neurosci 37(1): 31-39.

30. Opial D, Boehnke M, Tadesse S, Lietz Partzsch A, Flammer J, et al. (2001) Leber's hereditary optic neuropathy mitochondrial DNA mutations in normal-tension glaucoma. Graefe's archive for clinical and experimental ophthalmology $=$ Albrecht von Graefes Archiv fur klinische und experimentelle Ophthalmologie 239(6): 437-440.

31. Konieczka K, Flammer J, Sternbuch J, Binggeli T, Fraenkl S (2017) Leber's Hereditary Optic Neuropathy, Normal Tension Glaucoma, and Flammer Syndrome: Long Term Follow-up of a Patient. Klinische Monatsblatter fur Augenheilkunde.

32. Killer HE (2013) Compartment syndromes of the optic nerve and openangle glaucoma. Journal of glaucoma. 22(Suppl 5): S19-20.
33. Killer HE, Jaggi GP, Flammer J, Miller NR (2008) Is open-angle glaucoma caused by impaired cerebrospinal fluid circulation: around the optic nerve? Clin Experiment Ophthalmol 36(4): 308-311.

34. Konieczka K, Todorova MG, Bojinova RI, Binggeli T, Chackathayil TN, et al. (2016) Unexpected Effect of Calcium Channel Blockers on the Optic Nerve Compartment Syndrome. Klinische Monatsblatter fur Augenheilkunde. 233(4): 387-390.

35. Konieczka K, Flammer AJ, Todorova M, Meyer P, Flammer J (2012) Retinitis pigmentosa and ocular blood flow. The EPMA journal 3(1): 17.

36. Konieczka K, Koch S, Schoetzau A, Todorova MG (2016) Increased Prevalence of Flammer Syndrome in Patients with Retinitis Pigmentosa. Klinische Monatsblatter fur Augenheilkunde 233(4): 448-452.

37. Todorova MG, Josifova T, Konieczka K (2015) Endothelin-1 Plasma Levels in Patients with both Retinitis Pigmentosa and Flammer Syndrome. Klinische Monatsblatter fur Augenheilkunde 232(4): 514-518.

38. Ferrari S, Di Iorio E, Barbaro V, Ponzin D, Sorrentino FS, et al. (2011) Retinitis pigmentosa: genes and disease mechanisms. Curr Genomics 12(4): 238-249

39. Cellini M, Strobbe E, Gizzi C, Campos EC (2010) ET-1 plasma levels and ocular blood flow in retinitis pigmentosa. Can J Physiol Pharmacol 88(6): 630-635.

40. Falsini B, Anselmi GM, Marangoni D, D’Esposito F, Fadda A, et al. (2011) Subfoveal choroidal blood flow and central retinal function in retinitis pigmentosa. Investigative ophthalmology \& visual science 52(2): 10641069.

41. Lang M, Harris A, Ciulla TA, Siesky B, Patel P, et al. (2019) Vascular dysfunction in retinitis pigmentosa. Acta Ophthalmol 97(7): 660-664.

42. Wolf S, Postgens H, Bertram B, Schulte K, Teping C, et al. (1991) [Hemodynamic findings in patients with retinitis pigmentosa]. Klinische Monatsblatter fur Augenheilkunde 199(5): 325-329.

43. Narayan DS, Wood JP, Chidlow G, Casson RJ (2016) A review of the mechanisms of cone degeneration in retinitis pigmentosa. Acta Ophthalmol 94(8): 748-754.

44. Gaspar AZ, Flammer J, Hendrickson P (1994) Influence of nifedipine on the visual fields of patients with optic-nerve-head diseases. Eur J Ophthalmol 4(1): 24-28.

45. Terelak Borys B, Grabska Liberek I, Piekarniak Wozniak A, Konieczka $\mathrm{K}$ (2017) Choroidal infarction in a glaucoma patient with Flammer syndrome: a case report with a long-term follow-up. BMC ophthalmology 17(1): 23.

46. Konieczka K, Todorova MG, Chackathayil TN, Henrich PB (2015) Cilioretinal artery occlusion in a young patient with flammer syndrome and increased retinal venous pressure. Klinische Monatsblatter fur Augenheilkunde. 232(4): 576-578.

47. Flammer J, Kaiser H, Haufschild T (2001) Susac syndrome: a vasospastic disorder? Eur J Ophthalmol. 11(2): 175-179.

48. Bojinova RI, Konieczka K, Meyer P, Todorova MG (2016) The trilateral link between anaesthesia, perioperative visual loss and Flammer syndrome. BMC Anesthesiol 16: 10.

49. Bojinova RI, Konieczka K, Todorova MG (2016) Unilateral Loss of Vision after Spinal Surgery in a Patient with Flammer Syndrome. Klinische Monatsblatter fur Augenheilkunde 233(4): 429-431.

50. Fraenkl SA, Mozaffarieh M, Flammer J (2010) Retinal vein occlusions: The potential impact of a dysregulation of the retinal veins. The EPMA journal 1(2): 253-261.

51. Flammer J, Konieczka K (2015) Retinal venous pressure: the role of endothelin. The EPMA journal 6: 21.

52. Mozaffarieh M, Bartschi M, Henrich PB, Schoetzau A, Flammer J (2014) Retinal venous pressure in the non-affected eye of patients with retinal vein occlusions. Graefe's archive for clinical and experimental ophthalmology $=$ Albrecht von Graefes Archiv fur klinische und experimentelle Ophthalmologie 252(10): 1569-1571. 
53. Prunte C, Flammer J (1996) Choroidal capillary and venous congestion in central serous chorioretinopathy. American journal of ophthalmology 121(1): 26-34

54. Salvatore S, Vingolo EM (2010) Endothelin-1 role in human eye: A review. J Ophthalmol 2010: 354645 .

55. Schankin CJ, Maniyar FH, Digre KB, Goadsby PJ (2014) 'Visual snow' - a disorder distinct from persistent migraine aura. Brain 137(Pt 5): 14191428.

56. Gherghel D, Orgul S, Gugleta K, Flammer J (2001) Retrobulbar blood flow in glaucoma patients with nocturnal over-dipping in systemic blood pressure. American journal of ophthalmology 132(5): 641-647.

57. Gasser P, Stumpfig D, Schotzau A (1999) Ackermann-Liebrich U, Flammer J. Body mass index in glaucoma. Journal of glaucoma 8(1): 8-11.

58. Teuchner B, Orgul S, Ulmer H, Haufschild T, Flammer J (2004) Reduced thirst in patients with a vasospastic syndrome. Acta Ophthalmol Scand 82(6): 738-740.

59. Anders D, Vollenweider S, Cann J, Hofstetter M, Flammer J, et al. (2010) Heart-rate variability in women during 40-hour prolonged wakefulness. Chronobiol Int 27(8): 1609-1628.

60. Yeghiazaryan K, Flammer J, Orgul S, Wunderlich K, Golubnitschaja O (2009) Vasospastic individuals demonstrate significant similarity to glaucoma patients as revealed by gene expression profiling in circulating leukocytes. Mol Vis 15: 2339-2348.

61. Mozaffarieh M, Schoetzau A, Sauter M, Grieshaber M, Orgul S, et al. (2008) Comet assay analysis of single-stranded DNA breaks in circulating leukocytes of glaucoma patients. Mol Vis 14: 1584-1588.

62. Konieczka K, Koch S, Binggeli T, Schoetzau A, Kesselring J (2016) Multiple sclerosis and primary vascular dysregulation (Flammer syndrome). The EPMA journal 7:13.

ISSN: 2574-1241

DOI: 10.26717/BJSTR.2020.25.004193

Katarzyna Konieczka. Biomed J Sci \& Tech Res

(C) This work is licensed under Creative Commons Attribution 4.0 License

Submission Link: https://biomedres.us/submit-manuscript.php
63. Flammer J, Pache M, Resink T (2001) Vasospasm, its role in the pathogenesis of diseases with reference to the eye. Progress in retinal and eye research 20(3): 319-349.

64.Zubor P, Gondova A, Polivka J, Kasajova P, Konieczka K, et al. (2017) Breast cancer and Flammer syndrome: any symptoms in common for prediction, prevention and personalised medical approach? The EPMA Journal 8(2):129-140.

65. Smokovski I, Risteski M, Polivka J, Zubor P, Konieczka K, et al. (2017) Postmenopausal breast cancer: European challenge and innovative concepts. The EPMA journal 8(2): 159-169.

66. Bubnov R, Polivka J, Zubor P, Konieczka K, Golubnitschaja O (2017) Premetastatic niches in breast cancer: are they created by or prior to the tumour onset? Flammer Syndrome relevance to address the question. The EPMA journal 8(2): 141-157.

67. Gass A, Flammer J, Linder L, Romerio SC, Gasser P, et al. (1997) Inverse correlation between endothelin-1-induced peripheral microvascular vasoconstriction and blood pressure in glaucoma patients. Graefe's archive for clinical and experimental ophthalmology = Albrecht von Graefes Archiv fur klinische und experimentelle Ophthalmologie 235(10): 634-638.

68. Neumann T, Baertschi M, Vilser W, Drinda S, Franz M, et al. (2016) Retinal vessel regulation at high altitudes1. Clin Hemorheol Microcirc.

69. Baertschi M, Dayhaw Barker P, Flammer J (2015) The effect of hypoxia on intra-ocular, mean arterial, retinal venous and ocular perfusion pressures. Clin Hemorheol Microcirc.

70. Heitmar R, Gherghel D, Armstrong R, Cubbidge R, Hosking S (2008) The effect of voluntary fasting and dehydration on flicker-induced retinal vascular dilation in a healthy individual: A case report J Med Case Rep 2: 153.

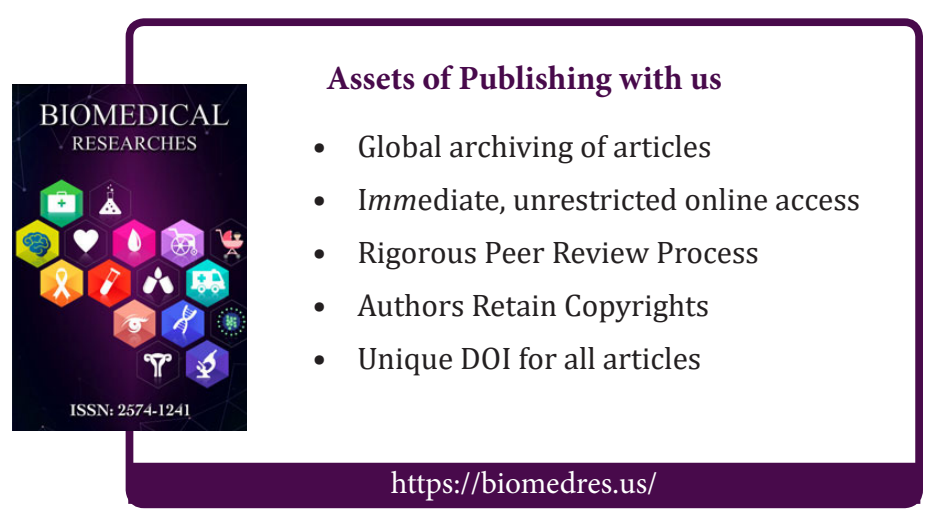

Copyright@ Katarzyna Konieczka | Biomed J Sci \& Tech Res | BJSTR. MS.ID.004193. 